\title{
Characteristics of Poker Flat Incoherent Scatter Radar (PFISR) naturally enhanced ion-acoustic lines (NEIALs) in relation to auroral forms
}

\author{
R. G. Michell ${ }^{1, * * * *}$, T. Grydeland ${ }^{2}$, and M. Samara ${ }^{1, * *}$ \\ ${ }^{1}$ Southwest Research Institute, San Antonio, Texas, USA \\ ${ }^{2}$ Norut, Northern Research Institute, Troms $\varnothing$, Norway \\ * currently at: University of Maryland, College Park, MD, USA \\ ** currently at: NASA Goddard Space Flight Center, Greenbelt, MD, USA
}

Correspondence to: R. G. Michell (robert.g.michell@ nasa.gov)

Received: 30 December 2013 - Revised: 14 September 2014 - Accepted: 17 September 2014 - Published: 29 October 2014

\begin{abstract}
Naturally enhanced ion-acoustic lines (NEIALs) have been observed with the Poker Flat Incoherent Scatter Radar (PFISR) ever since it began operating in 2006. The nearly continuous operation of PFISR since then has led to a large number of NEIAL observations from there, where common-volume, high-resolution auroral imaging data are available. We aim to systematically distinguish the different types of auroral forms that are associated with different NEIAL features, including spectral shape and altitude extent. We believe that NEIALs occur with a continuum of morphological characteristics, although we find that most NEIALs observed with PFISR fall into two general categories. The first group occurs at fairly low altitudes $-\mathrm{F}$ region or below - and have power at, and spread between, the ion-acoustic peaks. The second group contains the type of NEIALs that have previously been observed with the EISCAT radars, those that extend to high altitudes $(600 \mathrm{~km}$ or more) and often have large asymmetries in the power enhancements between the two ion-acoustic shoulders. We find that there is a correlation between the auroral structures and the type of NEIALs observed, and that the auroral structures present during NEIAL events are consistent with the likely NEIAL generation mechanisms inferred in each case. The first type of NEIAL - low altitude - is the most commonly observed with PFISR and is most often associated with active, structured auroral arcs, such as substorm growth phase, and onset arcs and are likely generated by Langmuir turbulence. The second type of NEIAL - high altitude - occurs less frequently in the PFISR radar and is associated with aurora that contains large fluxes of low-energy electrons, as can
\end{abstract}

happen in poleward boundary intensifications as well as at substorm onset and is likely the result of current-driven instabilities and in some cases Langmuir turbulence as well. In addition, a preliminary auroral photometry analysis revealed that there is an anticorrelation between the altitude of the NEIALs and the calculated energy of the electrons, which is consistent with the hypotheses presented here regarding generation mechanisms.

Keywords. Atmospheric composition and structure (airglow and aurora) - magnetospheric physics (plasma waves and instabilities) - radio science (waves in plasma)

\section{Introduction}

Naturally enhanced ion-acoustic lines (NEIALs), having been first observed with the Millstone Hill incoherent scatter radar in the late 1980s (Foster et al., 1988), were initially found to be associated with auroral structures (Collis et al., 1991; Rietveld et al., 1991). These early correlations between NEIALs and auroral observations were general and on a large scale. Further combining of auroral imaging with radar studies using the European Incoherent SCATter (EISCAT) radars was done by Sedgemore-Schulthess et al. (1999), Grydeland et al. $(2003,2004)$ and Blixt et al. (2005). These more recent - studies found correlations between the occurrence of smaller-scale auroral structures and the presence of NEIALs in the radar returns. The work of Blixt et al. (2005) was the next step in making specific correlations between 
NEIALs and auroral features. They presented narrow-fieldof-view (FOV) television observations of the aurora during four NEIAL events using the EISCAT Svalbard Radar (ESR). These observations constituted the first high spatial and temporal imaging observations of the aurora coincident with NEIAL observations on the dayside. On the nightside, Michell et al. (2008a) reported NEIAL observations with the Poker Flat Incoherent Scatter Radar (PFISR) which were also combined with common-volume auroral imaging at high spatial and temporal resolution.

These studies all reveal that NEIALs are correlated with auroral forms. The EISCAT observations found NEIALs to be associated with "flaming" aurora and tall, rayed aurora, indicative of large fluxes of low-energy electrons (Blixt et al., 2005). The PFISR observations found NEIALs to occur with dynamic small-scale auroral structures, particularly associated with substorm-onset aurora containing rayed arcs and the edges of thin, dynamic auroral features (Michell et al., 2009; Michell and Samara, 2010). Additionally using PFISR, Michell et al. (2008a) found NEIALs to occur at the poleward edge of a large-scale active auroral arc system that exhibited $\Omega$ band features.

It has been clearly established that NEIALs occur inside regions of auroral activity, but the specifics of the auroral structures associated with NEIALs have only been examined for a few case studies. It is the purpose of this article to present and discuss the specific auroral structures - large and small scale - that are correlated with the characteristics of NEIALs, specifically their spectral shape and altitude extent.

Determining the generation mechanisms of the enhanced wave activity responsible for causing NEIALs is an active area of research. There are theories that are consistent with the observations, but it is still an open question as to which theories are likely correct under which situations. The original ion-electron two-stream instability suggested by Foster et al. (1988) is consistent with the midlatitude observations but has been shown by Grydeland et al. $(2003,2004)$ to be inconsistent with some high-latitude NEIALs - where both shoulders are simultaneously enhanced.

Recent modeling efforts of NEIAL generation mechanisms include a range of possible theories, including enhanced ion-acoustic waves being driven by electrostatic ion cyclotron waves (Bahcivan and Cosgrove, 2008), or cold electron beams (Daldorff et al., 2007). However, the most likely - and currently accepted - mechanism for generating high-latitude NEIALs - originally proposed by Forme (1993) - is the electron-beam-driven Langmuir wave instability, by which enhanced Langmuir waves decay into ion-acoustic waves. This process has been termed Langmuir turbulence (LT), which has been recently modeled in more detail (Guio and Forme, 2006; Isham et al., 2012). There are two regimes of LT. At lower electron beam energies, the decay mechanism dominates (called "cascading" or "weak" LT), while at higher electron beam energies the cavitation mechanism
Table 1. Summary of the characteristics for the main high-latitude radars, specifically the operating frequency, the Bragg scattering scale length $(\lambda / 2)$, the magnetic latitude and the beam width.

\begin{tabular}{lrrrr}
\hline Radar & Freq. $(\mathrm{MHz})$ & $\lambda / 2(\mathrm{~cm})$ & Mag. lat. & Beamwidth \\
\hline EISCAT VHF & 224 & 67 & $66.2^{\circ}$ & $1.5^{\circ}$ \\
PFISR & 449 & 33 & $66.1^{\circ}$ & $1^{\circ}$ \\
ESR & 500 & 30 & $75.2^{\circ}$ & $0.6^{\circ}$ \\
EISCAT UHF & 933 & 16 & $66.2^{\circ}$ & $0.5^{\circ}$ \\
Sondrestrom & 1290 & 11 & $74.2^{\circ}$ & $0.5^{\circ}$ \\
\hline
\end{tabular}

dominates (called "cavitating" or "strong" LT). The possible NEIAL generation mechanisms should therefore be made to include processes that generate enhanced Langmuir waves.

Observations of simultaneously enhanced ion and plasma lines were first reported by Rietveld et al. (2002), and those same observations have since been further analyzed and simulated by Isham et al. (2012). Using ESR data, Strømme et al. (2005) found a correlation between enhanced Langmuir waves, as evidenced by enhanced plasma line power in the radar data, and NEIALs. In addition, Sullivan et al. (2008) used a numerical technique to calculate energy inputs by inverting optical auroral observations. The detailed auroral structures - and inferred electron energies - that occur with NEIALs can provide additional information for determining the in situ electrodynamics related to the generation mechanisms.

\section{Instrumentaion}

\subsection{Radars}

The NEIALs that were observed with PFISR and the accompanying high-resolution auroral imaging data are the main observations that were focused on for this analysis. However, it is important to note the major differences between the PFISR radar and the other high-latitude incoherent scatter radars and their NEIAL observations. Table 1 summarizes the relevant parameters for the five main radars in the auroral zone. The ESR radar, at the highest magnetic latitude, lies under the cusp on the dayside and therefore typically observes different types of auroral structures than the EISCAT mainland (UHF and VHF) radars which are located at the equatorward edge of the nightside auroral oval. PFISR is also located at the equatorward edge of the nightside auroral oval and thus is positioned to observe active, substorm-onsettype aurora and the associated NEIALs (Michell et al., 2009; Michell and Samara, 2010).

The two mainland EISCAT radars and the PFISR radar should therefore observe comparable auroral structures, but the operating frequencies of the radars are different; therefore it would not be relevant to compare the NEIAL observations between the radars for this study. NEIALs have been observed with both EISCAT mainland radars at the 
different operating frequencies, both UHF $(933 \mathrm{MHz})$ and VHF (224 MHz) (Collis et al., 1991; Cabrit et al., 1996), as well as with the ESR radar at high magnetic latitude (Blixt et al., 2005), under the cusp/dayside auroral oval. The Sondrestrom radar, which is at a similar latitude to ESR, operates at a higher frequency of $1290 \mathrm{MHz}$, and no NEIALs have been observed there yet (Strømme, 2004), despite the presence of active aurora containing tall, rayed auroral arcs at the polar cap boundary. Michell and Samara (2013) conducted a specific study at Sondrestrom, examining the radar data at times when active and dynamic auroral structures were present in the radar beam, and found no evidence of NEIALs in the Sondrestrom radar data, suggesting a limiting scale size over which the enhanced ion-acoustic wave activity can occur.

The aim of this study is to examine the differences between NEIALs that were observed with different types of auroral structures; therefore data from only one radar will be used, so that the differences observed correspond only to those associated with the different auroral conditions. Data from the PFISR radar are chosen because the auroral season of 2011 and 2012 had a marked increase in auroral activity with the onset of solar maximum where many active auroral displays occurred over Poker Flat. In addition, the Multi-spectral Observatory Of Sensitive EMCCD (MOOSE) imagers were in operation nearly the whole winter, providing high-resolution imaging of the auroral structures. The PFISR data used are from the magnetic zenith where uncoded long pulses $(450 \mu \mathrm{s})$ were used in order to gain maximum spectral information from the $\mathrm{F}$ region ionosphere. This pulse length leads to altitude smearing of $\sim 70 \mathrm{~km}$. All the radar spectra in this paper were formed by applying a Hanning window to the estimated ACFs (auto correlation functions) before doing the discrete Fourier transforms. This helps to reduce variance and spectral leakage, which would otherwise dominate the spectrum at the frequencies near sharp peaks.

\subsection{Optical}

The first several years of PFISR operation corresponded to a long, geomagnetically quiet solar minimum. During this time there were only a few NEIALs observed with PFISR where simultaneous auroral imaging was possible. The recent increases in solar activity have resulted in significantly more active auroral structures over the PFISR radar. This has resulted in a significant increase in the number of NEIALs observed with PFISR. The addition of the MOOSE imagers to Poker Flat in September 2011 have greatly increased the auroral imaging capabilities available.

The MOOSE imagers used to make the auroral observations were Andor Ixon DU-888 EMCCD (Electron Multiplying Charge Coupled Device) imagers. These have a $1024 \times 1024$ pixel chip, with internal binning capabilities that allow tradeoffs between temporal and spatial resolution. For the observations presented, the MOOSE imagers were

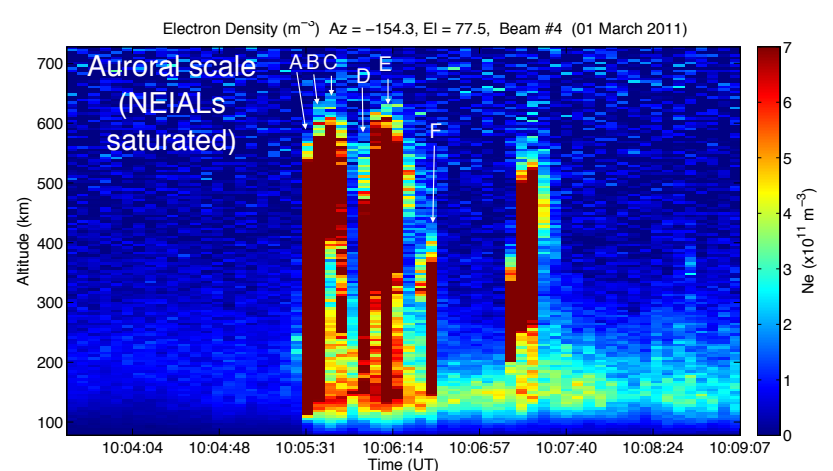

Electron Density $\left(m^{-3}\right) \quad A z=-154.3, E l=77.5$, Beam \#4 01 March 2011

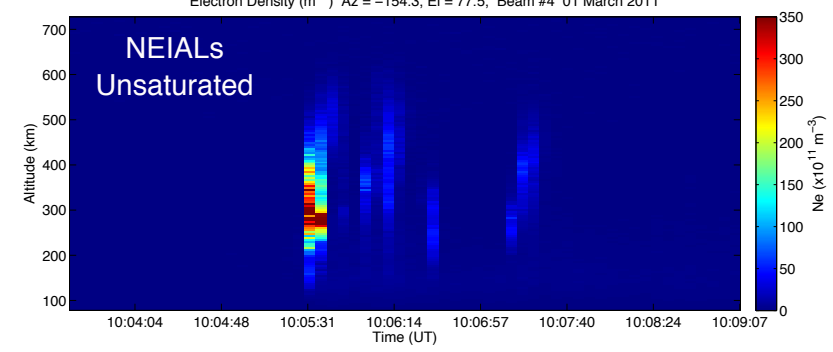

Figure 1. Event 1: top: PFISR electron density profiles, covering a time period of about $6 \mathrm{~min}$ around substorm onset. The strong NEIAL returns can be seen to extend from $120 \mathrm{~km}$ up to $600 \mathrm{~km}$ altitude. The times marked A-F are the times of the NEIAL spectra shown in Fig. 2. Bottom: same time period with intensity scale set so the NEIALs are not oversaturated.

operating with both all-sky and narrow-field-of-view $\left(15^{\circ}\right.$ FOV) lenses. Table 2 shows the summary of imager configurations used with filter, field of view, frame rate and emission line characteristics. The CCDs were cooled to $-70^{\circ} \mathrm{C}$ to reduce thermal noise and the narrow-field imagers were set to $4 \times 4$ binning (with a small degree of sub-framing), resulting in a $190 \times 190$ image at 40.7 frames per second $(\sim 20 \mathrm{~ms}$ exposure time). The all-sky imagers were set to $2 \times 2$ binning, resulting in a $512 \times 512$ image at 3.3 frames per second ( $\sim 300 \mathrm{~ms}$ exposure time). This configuration was chosen because it provides adequate temporal resolution at the large scale (all sky) while still getting high temporal and spatial resolution at the small scales with the narrow-field imagers. This setup provides an angular resolution of $0.054^{\circ}$ per pixel or approximately $100 \mathrm{~m}$ per pixel for the narrow field and 600 to $800 \mathrm{~m}$ per pixel for the all-sky images in the vicinity of the zenith, assuming an auroral emissions altitude of $100 \mathrm{~km}$. The narrow-field imagers were pointed to the magnetic zenith, which is near the center of the all-sky images. All of the auroral images presented here are oriented such that north is at the bottom and east is to the right (i.e. a view from below).

The narrow-field images presented below were taken in the $427.8 \mathrm{~nm}$ emission line - from $\mathrm{N}_{2}^{+}$- which is a prompt emission, enabling a one-to-one correspondence between the electron precipitation and the auroral luminosity. Event 1, however, was only imaged with a BG3 filter - described 
Table 2. Summary of the auroral imager operations during the 2011-2012 auroral season, when these NEIAL observations were made.

\begin{tabular}{lrrll}
\hline Field of view (degrees) & Frame rate $(\mathrm{Hz})$ & Filter $(\mathrm{nm})$ & Lifetime & Avg. altitude $(\mathrm{km})$ \\
\hline All-sky $\left(180^{\circ}\right)$ & 3.3 & 557.7 & Slow $(0.7 \mathrm{~s})$ & $100-120$ \\
Narrow $\left(15^{\circ}\right)$ & 40.7 & 427.8 & Prompt $(\sim \mathrm{ns})$ & $100-120$ \\
Narrow $\left(15^{\circ}\right)$ & 40.7 & 844.6 & Prompt $(\sim \mathrm{ns})$ & $200-250$ \\
Narrow $\left(15^{\circ}\right)$ & 40.7 & 630.0 & Slow $(110 \mathrm{~s})$ & $200-250$ \\
Narrow $\left(15^{\circ}\right)$ & 40.7 & BG3 & Prompt $(\sim \mathrm{ns})$ & $100-120$ \\
\hline
\end{tabular}
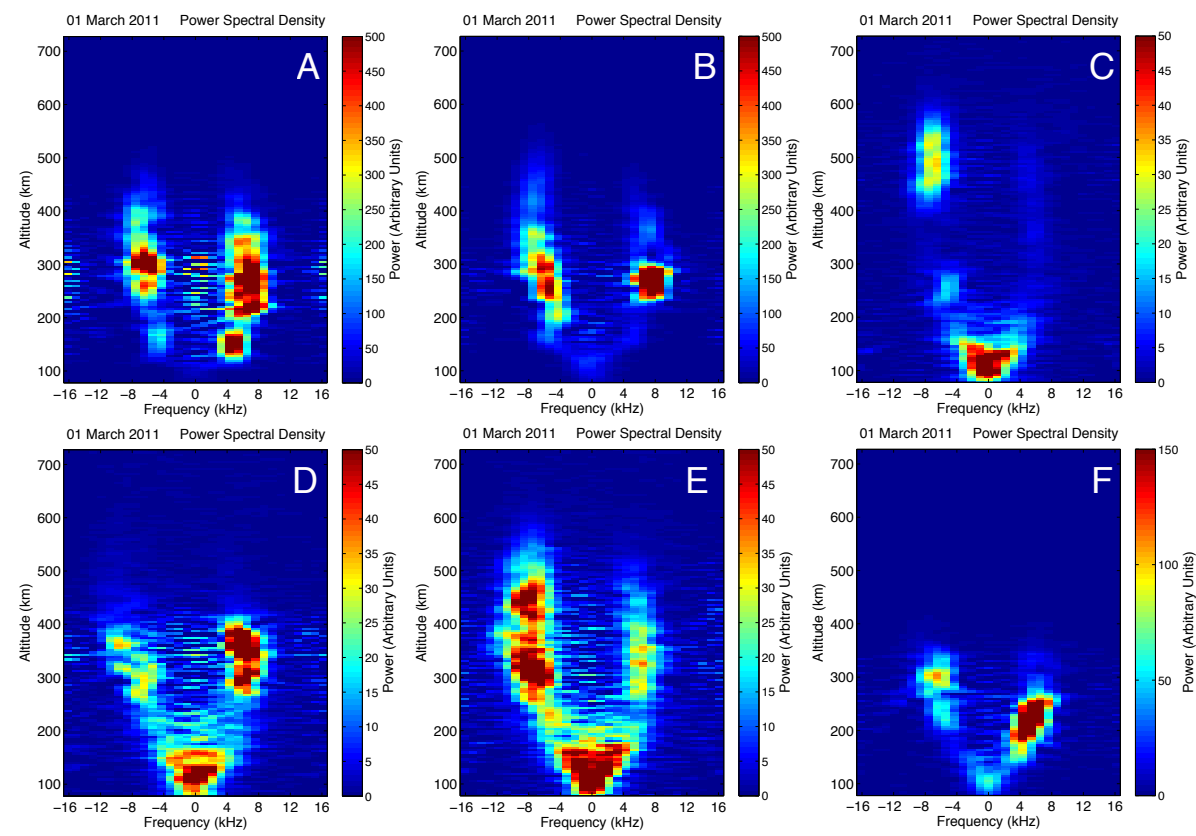

Figure 2. Event 1: NEIAL spectra from the times labeled A-F in Fig. 1. There is a large variation in the spectral features between the $5 \mathrm{~s}$ integration periods during this event. Overall the downshifted shoulder was more enhanced than the upshifted shoulder. Note that the intensity scale is not the same for each spectrum, due to the extreme variation in NEIAL intensity.

below - because that was the only narrow-field imaging available for that event. A full analysis of the emission line characteristics of the auroral coincident with the NEIALs is beyond the scope of this paper, but a preliminary estimate of the average precipitating electron energy can be made for Events 2 through 5 . For the auroral photometry and the initial electron energy estimates, the intensities of these other emission lines are needed. The $844.6 \mathrm{~nm}$ emission line from atomic oxygen is also a prompt emission that is primarily excited in the $\mathrm{F}$ region. The other two emission from atomic oxygen are 557.7 and $630.0 \mathrm{~nm}$, which are both slow emissions with lifetimes of 0.7 and $110 \mathrm{~s}$, respectively. The $557.7 \mathrm{~nm}$ emission comes primarily from the $\mathrm{E}$ region from around 100 to $120 \mathrm{~km}$ altitude, while the $630.0 \mathrm{~nm}$ emission comes primarily from the $\mathrm{F}$ region at around 200 to $250 \mathrm{~km}$ altitude. The differences in altitude do not affect the analysis because the emissions are taken in the magnetic zenith and are therefore measured as a column-integrated intensity along the magnetic field.
There are several published methods for estimating the average electron energy based on auroral emission line ratios (Rees and Luckey, 1974; Hecht et al., 2006). One of the methods discussed in Hecht et al. (2006) uses the ratio of the 844.6 to $427.8 \mathrm{~nm}$ emissions, which are both prompt, enabling accurate estimates to be made on the fast timescales of the small-scale aurora. The preliminary electron energy estimates presented here are based on the ratio of 844.6 to $427.8 \mathrm{~nm}$.

\section{Observations}

An examination of many NEIAL events $(\sim 20)$ that occurred during the winter of 2011 and 2012 revealed that the morphology of the NEIALs was consistently and predictably tied to the auroral morphology present. We discuss five example NEIALs observed along with the representative types of auroral structures present. These observations cover the broad range of aurora/NEIALs that are typically observed at Poker 


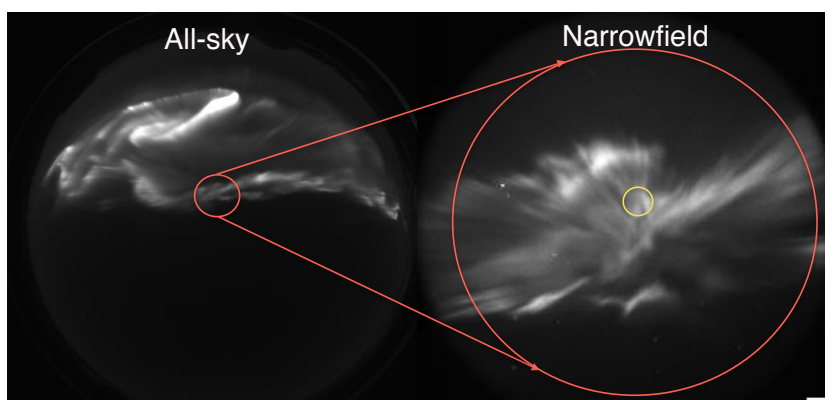

Figure 3. Event 1: all-sky image (left) - taken with $557.7 \mathrm{~nm}$ filter - and narrow-field image (right) - taken with a BG3 filter - showing the dynamic structured aurora at the time of the NEIALs in the PFISR data. The yellow circle near the center of the narrow-field image represents the location of the PFISR radar beam in the magnetic zenith. North is down and east is to the right.

Flat. There are variations of NEIAL characteristics between NEIALs observed at different times during the same night, but there are larger and systematic differences observable between NEIALs observed during separate auroral events. It is these large-scale systematic differences that we focus on in this article. This section describes and presents the NEIALs observed with five different types of auroral structures, summarized in Table 3, where each subsection will describe a different auroral event with differing NEIAL characteristics.

\subsection{Event 1: substorm onset with flaming aurora - 1 March 2011}

A substorm onset occurred over Poker Flat on 1 March 2011 at approximately 10:05 UT (22:45 MLT), where dynamic, highly structured aurora was observed in the magnetic zenith. During this time, strongly enhanced NEIALs were observed in the PFISR data. Figure 1 shows the electron density from PFISR - derived from scaled returned power - covering a period of 6 min around the substorm onset time. These NEIAL returns extend from $\sim 120 \mathrm{~km}$ up to $\sim 600 \mathrm{~km}$ altitude. The altitude profiles of the NEIAL spectra - for the times labeled A-F in Fig. 1 - are shown in Fig. 2. The spectral shape of the returns vary significantly between consecutive $-5 \mathrm{~s}-$ integration periods.

Figure 3 shows the auroral images from this time, an allsky image (left) and a narrow-field image (right). The all-sky image was taken in $557.7 \mathrm{~nm}$; the narrow-field image was taken with a Schott BG3 glass filter. The BG3 filter is used to examine only the prompt emissions; it is a notch filter that cuts out the region of the spectrum that contains the slow 557.7 and $630.0 \mathrm{~nm}$ emissions and lets in the prompt blue and near-infrared emissions. A transmission curve for the BG3 filter is reproduced in Semeter et al. (2008). The high time resolution of the image data reveals flaming aurora, with apparent motion of structures toward the magnetic zenith. Flaming aurora is indicative of energy-dispersed electron

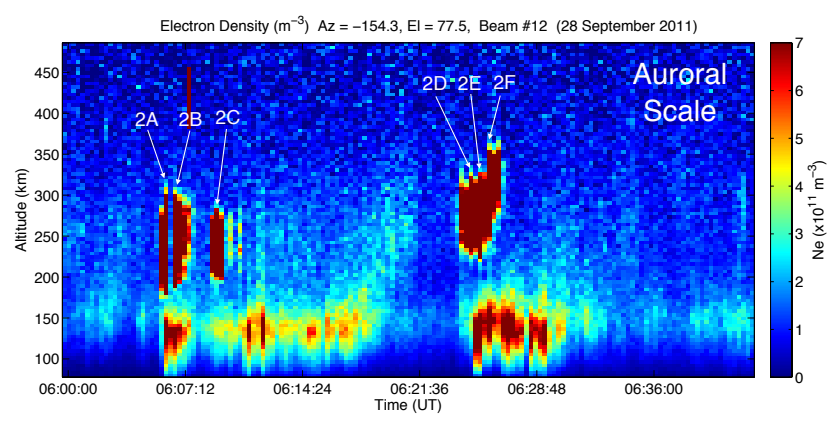

Electron Density $\left(m^{-3}\right) A z=-154,3, E 1=77,5$, Beam \#12 28 September 2011

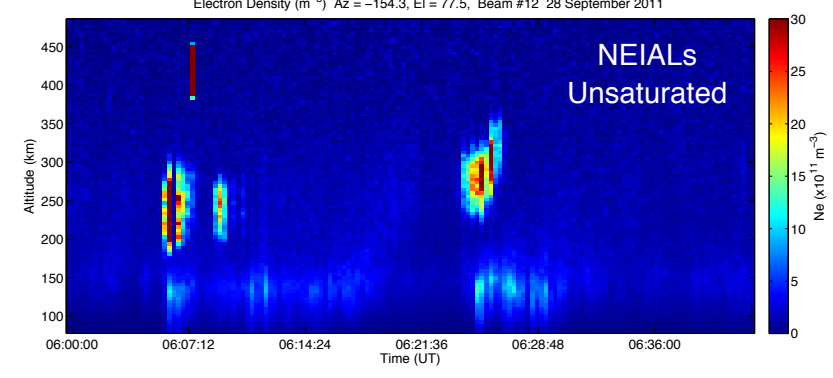

Figure 4. Event 2: top: PFISR electron density profiles, covering a time period of about $40 \mathrm{~min}$ with a thin, structured auroral arc in zenith. The strong NEIAL returns can be seen in a limited altitude range, mostly between 200 and $300 \mathrm{~km}$. The times marked 2A-2F are the times of the NEIAL spectra shown in Fig. 5. Bottom: same time period with intensity scale set so the NEIALs are not oversaturated.

precipitation (Dahlgren et al., 2013), with the highest energy electrons $(\sim 2 \mathrm{keV})$ reaching lower down $(\sim 120 \mathrm{~km})$ into the ionosphere first and then the lower energies $(\sim 0.8 \mathrm{keV})$ arriving later $(\sim 0.2 \mathrm{~s})$ and reaching to higher altitudes $(\sim 150 \mathrm{~km})$. This gives the appearance of upward propagation of the auroral light, which manifests - in the 2-D images - as motion towards the magnetic zenith.

The auroral imaging for this event was limited to one allsky camera (with $557.7 \mathrm{~nm}$ ) and one narrow-field camera (with BG3 filter). For all the following events discussed, the imager configurations listed in Table 2 were in operation.

\subsection{Event 2: active E-W arc - 28 September 2011}

An active auroral event was observed over Poker Flat on 28 September 2011. This event was composed of a largescale E-W-aligned auroral arc that contained significant substructure, including small-scale folds and fast ray motions. Figure 4 shows the PFISR electron density profiles covering a period of about $40 \mathrm{~min}$, which contained strong NEIAL enhancements associated with the auroral activity. The NEIALs can be seen between 200 and $300 \mathrm{~km}$ altitude, and several representative times are labeled $2 \mathrm{~A}-2 \mathrm{~F}$, where the spectra and auroral structures will be examined. Figure 5 shows the spectra of the NEIALs labeled $2 \mathrm{~A}-2 \mathrm{~F}$ in Fig. 4. This event shows no distinct asymmetry between the ion-acoustic peaks; in fact the returned power is distributed fairly evenly 
Table 3. Summary of the auroral events examined and the distinguishing NEIAL characteristics.

\begin{tabular}{cllcl}
\hline Event & Date & Type of aurora & MLT & NEIAL altitude range $(\mathrm{km})$ \\
\hline 1 & 1 Mar 2011 & Substorm onset: dynamic and structured & $22: 50$ & $120-600$ \\
2 & 28 Sep 2011 & East-west, growth-phase arc & $18: 45$ & $200-300$ \\
3 & 2 Oct 2011 & Arc with folds - flickering & $21: 45$ & $200-250$ and 300-400 \\
4 & 2 Oct 2011 & Pulsating aurora boundaries & $22: 50$ & $150-350$ \\
5 & 22 Jan 2012 & Tall rays - polar cap boundary & $23: 30$ & $100-700$ \\
\hline
\end{tabular}
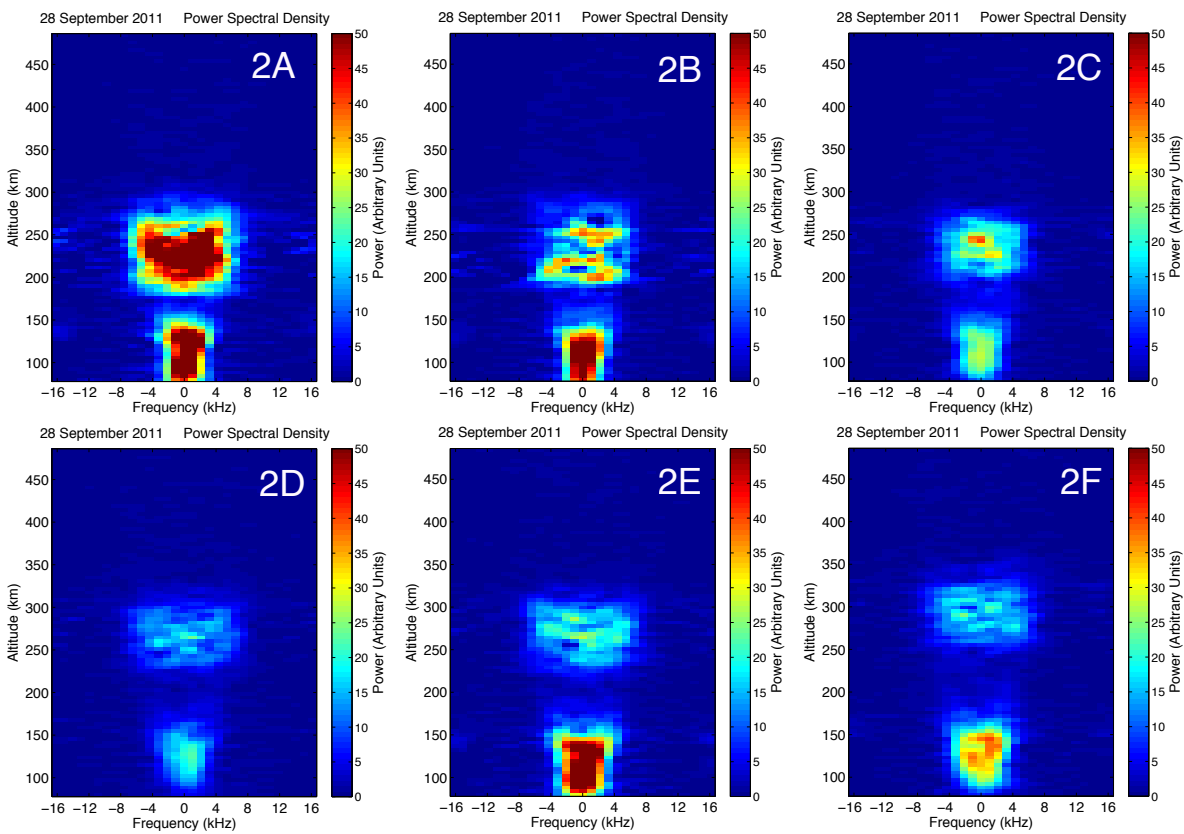

Figure 5. Event 2: NEIAL spectra from the times labeled $2 \mathrm{~A}-2 \mathrm{~F}$ in Fig. 4. There is little variation in the spectral features - other than intensity - between the 5 -second integration periods during this event. There are no distinct spectral asymmetries and primarily enhanced power in the whole spectral range between the up- and downshifted ion-acoustic lines.

between the ion-acoustic lines. In addition, the altitude of the NEIALs is low, extending from 200 to $350 \mathrm{~km}$ altitude.

Figure 6 shows the all-sky images of the $557.7 \mathrm{~nm}$ auroral emission at the times labeled $2 \mathrm{~A}-2 \mathrm{~F}$ in Fig. 4. These images are taken using a $300 \mathrm{~ms}$ exposure, and they show the overall auroral context during the event. The general east-west alignment of the arc structure is visible, along with the presence of several thin arcs in the north-south direction. The NEIALs occurred when the active equatorward edge of the thin auroral arc structure moved into the magnetic zenith. The NEIALs with the largest returned power $-2 \mathrm{~A}$ and $2 \mathrm{~B}$ - occurred when the aurora was brighter and more dynamic, although there were some thin clouds obscuring the view of the smallest-scale features. Figure 7 shows the narrow-field auroral images of the $427.8 \mathrm{~nm}$ emission at the times labeled $2 \mathrm{~A}-2 \mathrm{~F}$ in Fig. 4. These narrow-field images reveal the smallscale structure with the thin arc structures in the magnetic zenith, except for $2 \mathrm{~A}$ and $2 \mathrm{~B}$, where thin clouds partially blocked the view.

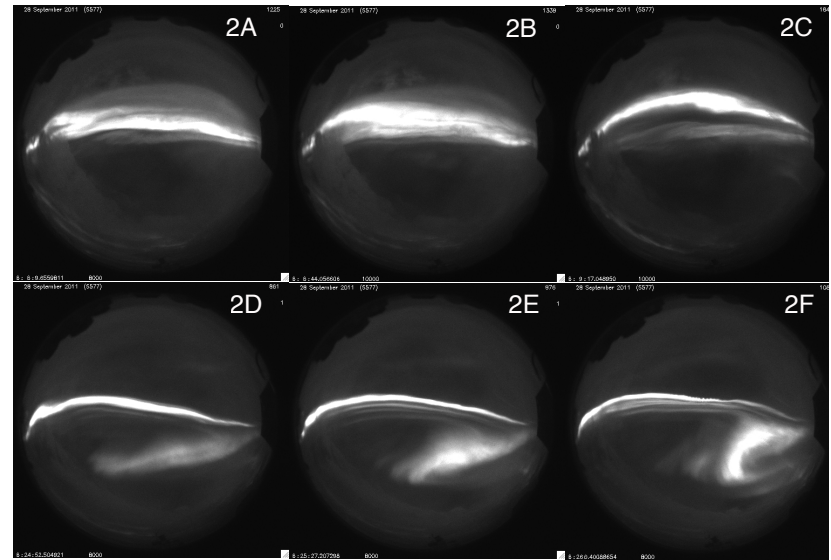

Figure 6. Event 2: all-sky images - taken on 28 September 2011 with a $557.7 \mathrm{~nm}$ filter - showing the dynamic overall structure of the aurora at the times of the NEIALs in the PFISR data (labeled $2 \mathrm{~A}-2 \mathrm{~F})$. In this orientation, north is down and east is to the right. 


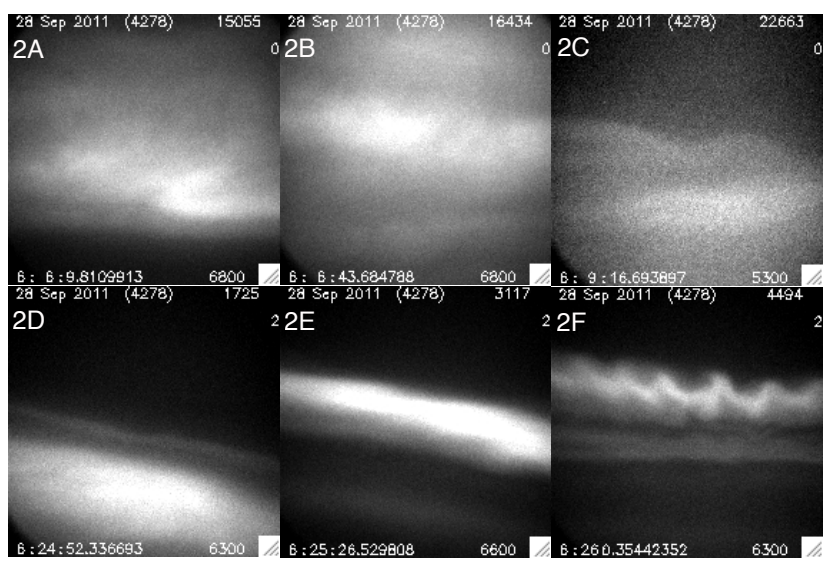

Figure 7. Event 2: narrow-field images $\left(15^{\circ}\right.$ FOV $)$ - taken on 28 September 2011 with a $427.8 \mathrm{~nm}$ filter - showing the small-scale structure of the aurora at the times of the NEIALs in the PFISR data (labeled 2A-2F). The magnetic zenith - the location of the radar beam $\left(\sim 1^{\circ}\right.$ beamwidth $)$ - is located near the center of each image. Same orientation as Fig. 6.

\subsection{Event 3: active E-W arc with folds - 2 October 2011}

The next auroral event examined was observed in the magnetic zenith at Poker Flat on 2 October 2011. This event is similar to Event 2 - described above - in that the active equatorward edge of the auroral oval was near the magnetic zenith and NEIALs were observed when the aurora moved into the zenith. However, this event contained more structure within the generally E-W-aligned auroral arc, with large-scale folds that eventually turn into $\mathrm{N}-\mathrm{S}$-aligned structures.

Figure 8 shows the PFISR electron density profiles covering a period of about $10 \mathrm{~min}$, which contained the strong NEIAL enhancements, labeled 3A-3F. The NEIALs occur in two distinct altitude ranges, in the $\mathrm{F}$ region between 300 and $400 \mathrm{~km}$ altitude and between the $\mathrm{E}$ and $\mathrm{F}$ regions at 200 to $250 \mathrm{~km}$ altitude. The spectra of each of these NEIALs (3A3F) are shown in Fig. 9. The intensity scale is set such that the structure within the NEIALs is clearly visible, but at this time the auroral $\mathrm{E}$ region was strongly enhanced due to the electron precipitation, causing the $\mathrm{E}$ region to appear saturated in the spectra. This event also shows that there is no overall spectral asymmetry in the NEIALs, although in some cases there is at certain altitudes, such as 3B at $250 \mathrm{~km}$ altitude. Although the NEIALs appear to cover distinct ranges in altitude, it should be noted that the pulse width of $450 \mu \mathrm{s}$ translates to an altitude range of $67.5 \mathrm{~km}$, which is the altitude range visible for the NEIALs on Fig. 8. Therefore all that can be determined about these NEIALs in terms of altitude extent was that they occurred somewhere within the $67.5 \mathrm{~km}$ altitude range, and it is possible that they could have occurred over a very narrow altitude range within that window.

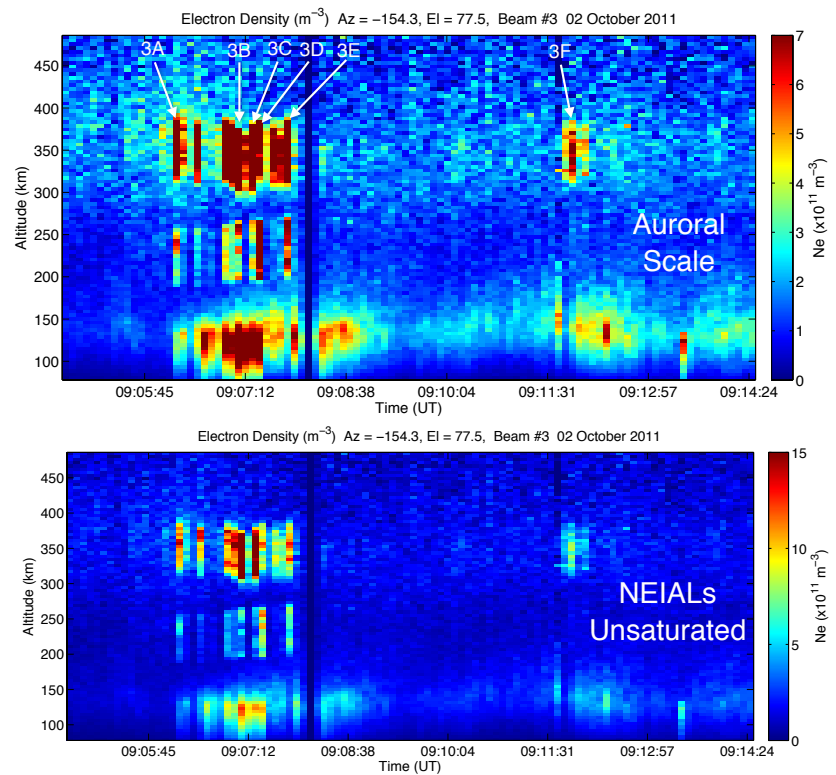

Figure 8. Event 3: top: PFISR electron density profiles, covering a time period of about $10 \mathrm{~min}$ with dynamic, highly structured and flickering aurora in zenith. The strong NEIAL returns can be seen in two limited altitude ranges, mostly between 200 and $250 \mathrm{~km}$ and between 300 and $400 \mathrm{~km}$. The times marked $3 \mathrm{~A}-3 \mathrm{~F}$ are the times of the NEIAL spectra shown in Fig. 9. Bottom: same time period with intensity scale set so the NEIALs are not oversaturated.

Figure 10 shows the all-sky images of the $557.7 \mathrm{~nm}$ auroral emission at the times labeled $3 \mathrm{~A}-3 \mathrm{~F}$ in Fig. 8. These images show that the overall arc structure is wider than in Event 2 and contains more folds and distortions along the arc. There are also some thin clouds which block some of the aurora from view, but the overall structure is clearly visible in the all-sky camera data. Figure 11 shows the narrow-field auroral images of the $427.8 \mathrm{~nm}$ emission at these same times, showing that there are dynamic small scale features present. The high time resolution of the image data reveals that there was flickering aurora (Michell et al., 2012) present at these times in addition to the fast motions of rays and folds along the arcs.

\subsection{Event 4: structured pulsating aurora - 2 October 2011}

Later on the night of 2 October 2011 - although still before magnetic midnight - the aurora had broken up into largescale irregularly shaped pulsating aurora. During a short period within this pulsating aurora, several distinct NEIAL features were observed in the PFISR returns. Figure 12 shows the PFISR electron density profiles covering a period of about $5 \mathrm{~min}$, which contained the NEIAL enhancements. The layer of enhanced electron density at $\sim 120 \mathrm{~km}$ altitude corresponds to the increased ionization resulting from the precipitating electrons causing the pulsating aurora. The first of 

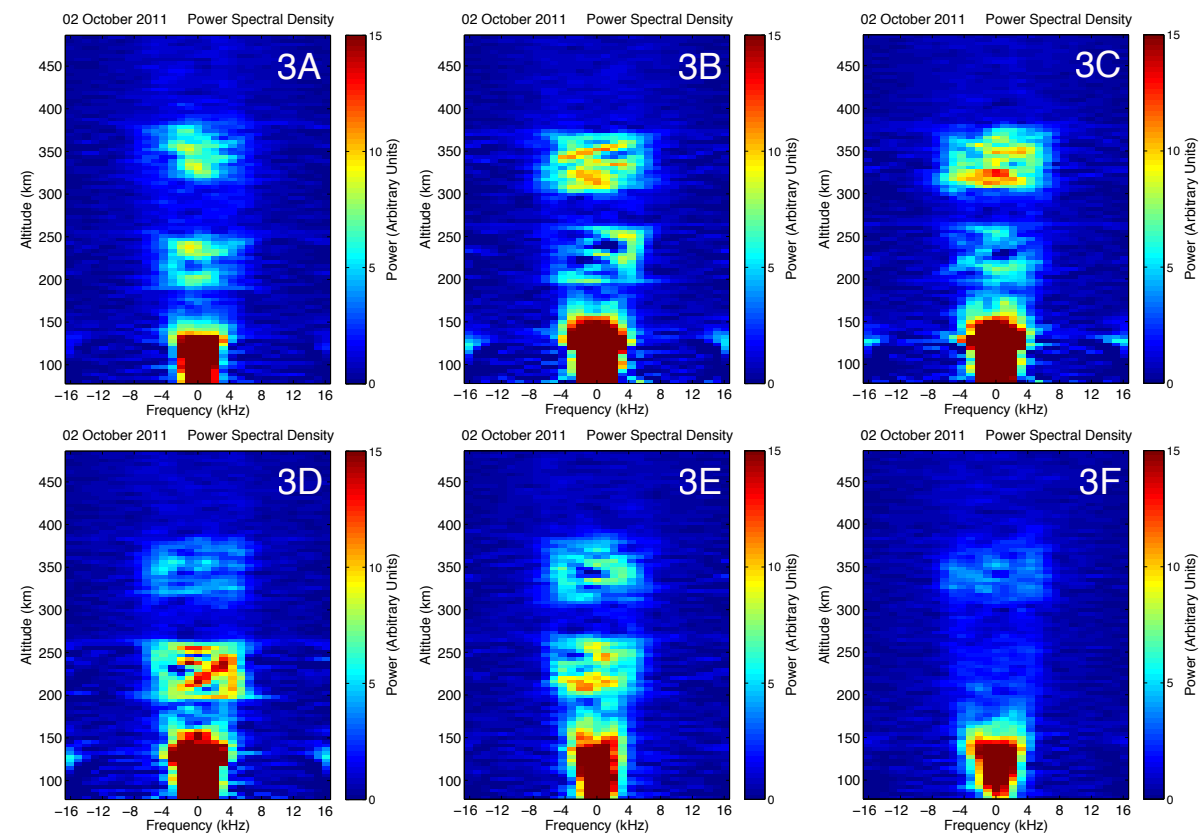

Figure 9. Event 3: NEIAL spectra from the times labeled 3A-3F in Fig. 8. There are no distinct spectral asymmetries and primarily enhanced power in the whole spectral range between the up- and downshifted ion-acoustic lines for both the higher- and lower-altitude ranges. The apparent saturation in the E region is caused by the strongly enhanced electron density due to the intense auroral precipitation present.

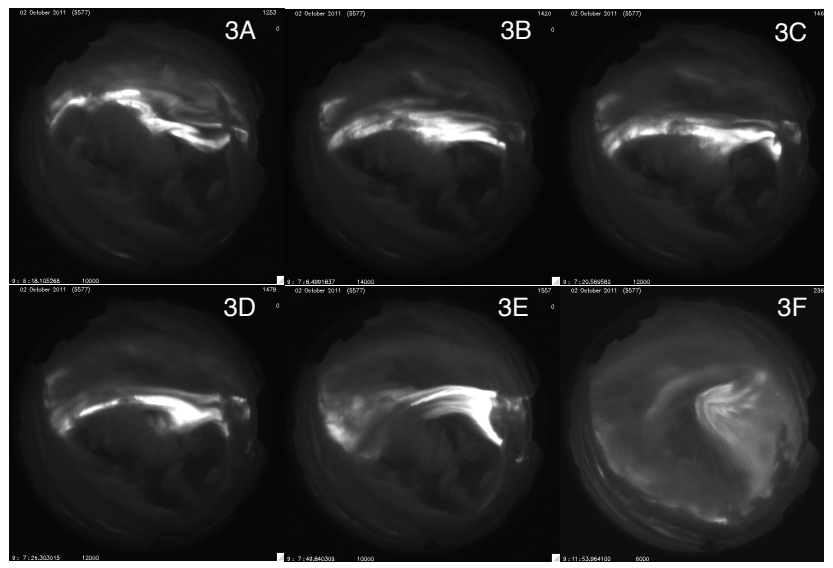

Figure 10. Event 3: all-sky images - taken on 2 October 2011 with a $557.7 \mathrm{~nm}$ filter - showing the dynamic overall structure of the aurora at the times of the NEIALs in the PFISR data (labeled 3A-3F). North is down and east is to the right.

the NEIAL returns occurred just above the $\mathrm{E}$ region, around 150 to $200 \mathrm{~km}$ altitude, labeled 4A and 4B. The third NEIAL, labeled $4 \mathrm{C}$, occurred within the $\mathrm{F}$ region between 250 and $350 \mathrm{~km}$ altitude.

The spectra of the NEIALs labeled 4A-4C in Fig. 12 are shown in Fig. 13. NEIAL 4A shows a strong enhancement of the downshifted ion-acoustic line, although there is some enhanced power extending into the zero-Doppler region. This is consistent with strong Langmuir turbulence as a

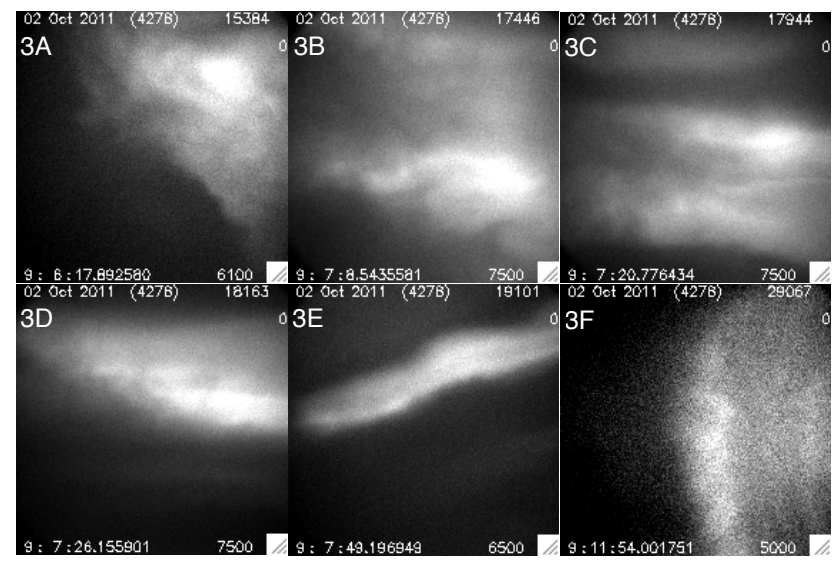

Figure 11. Event 3: narrow-field images $\left(15^{\circ} \mathrm{FOV}\right)-$ taken on 2 October 2011 with a $427.8 \mathrm{~nm}$ filter - showing the small-scale structure of the aurora at the times of the NEIALs in the PFISR data (labeled 3A-3F). The magnetic zenith - the location of the radar beam $\left(\sim 1^{\circ}\right.$ beamwidth $)$ - is located near the center of each image. Same orientation as Fig. 10.

possible generation mechanism, since such zero-Doppler enhancements have previously been modeled (Guio and Forme, 2006) and observed (Isham et al., 2012) to be caused by strong Langmuir turbulence. NEIAL 4B shows very strongly enhanced returns between 150 and $225 \mathrm{~km}$ altitude - so strong that it appears to have saturated the receiver. An examination of the raw power returns at this time reveal that the 
power is intermittent and at different altitudes within the integration time and range gate, which is consistent with these being of geophysical origin and not a range-aliased satellite return. It is not clear what is causing the low-altitude $(100 \mathrm{~km})$ return around $+14 \mathrm{kHz}$, but it is likely caused by a meteor or some interference not related to the aurora. NEIAL $4 \mathrm{C}$ shows returns between 250 and $300 \mathrm{~km}$ that appear very similar to those from Event 2, despite the presence of very different auroral structures.

Figure 14 shows the all-sky auroral images $-557.7 \mathrm{~nm}$ emission - at the times labeled $4 \mathrm{~A}-4 \mathrm{C}$ in Fig. 12. There are a few thin clouds present, but the overall large-scale diffuse and pulsating auroral structures are clearly visible. Near the center of the image, there is a boundary between two regions, and it is on this boundary that the NEIALs occurred. The narrow-field auroral images for these same times (4A-4C) are shown in Fig. 15 (again, these are taken with a $427.8 \mathrm{~nm}$ narrowband filter). The narrow-field images show less structure than all the previous examples, but they do show a distinct edge and dark region in the magnetic zenith at these times.

\subsection{Event 5: tall rays at the polar cap boundary (major storm time) - 22 January 2012}

A CME (coronal mass ejection) impacted Earth's magnetosphere on 22 January 2012, causing a geomagnetic storm. The auroral oval expanded during this storm such that the poleward boundary of the oval was over Poker Flat around magnetic midnight (11:20UT). Figure 16 shows the PFISR electron density profiles covering a period of about $45 \mathrm{~min}$, which contained many strong NEIAL enhancements. The times labeled $5 \mathrm{~A}-5 \mathrm{~F}$ are the example NEIALs where the spectra and auroral structures will be examined. Figure 17 shows the spectra of these NEIALs (labeled 5A-5F in Fig. 16). The enhanced power extends up to high altitudes - greater than $700 \mathrm{~km}$ in some cases - and contains significant asymmetry between the up- and downshifted ion lines.

The auroral features present during this time contained curtains of dynamic tall rays, consistent with polar cap boundary type aurora. The all-sky auroral images (in $557.7 \mathrm{~nm}$ ) from the times labeled 5A-5F in Fig. 16 are shown in Fig. 18. The poleward edge of the auroral oval is in the magnetic zenith at these times, and there is some degree of twisting and folding of the poleward-most curtain of tall rays in all of the examples. Figure 19 shows the narrow-field auroral images of the $427.8 \mathrm{~nm}$ emission at the times labeled $5 \mathrm{~A}-5 \mathrm{~F}$ in Fig. 16. These images show that the tall ray structures are visible, even in the $427.8 \mathrm{~nm}$ emission, indicating large fluxes of precipitating electrons, including high-energy (several $\mathrm{keV}$ ) electrons. The converging appearance of the rays towards the magnetic zenith results from the large altitude extent.

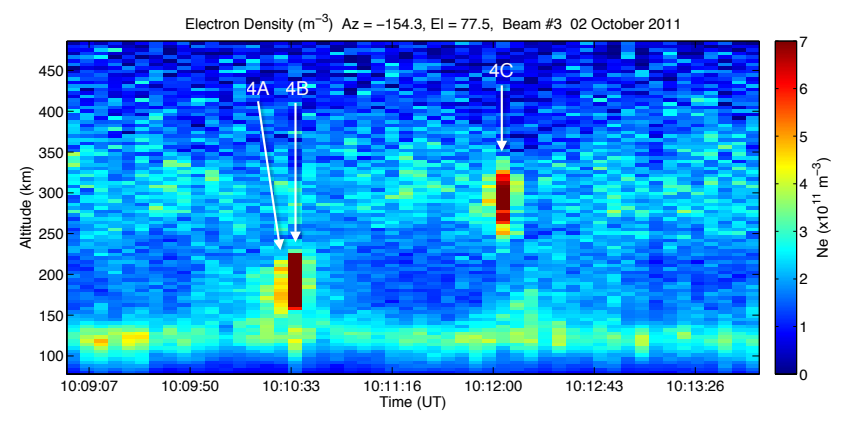

Figure 12. Event 4: PFISR electron density profiles, covering a time period of about $5 \mathrm{~min}$ with structured pulsating aurora in zenith. The strong NEIAL returns can be seen at two times and at different altitude ranges. The times marked $4 \mathrm{~A}-4 \mathrm{C}$ are the times of the NEIAL spectra shown in Fig. 13.

\section{Discussion}

The generation mechanisms for NEIALs remain largely unknown although there are many different candidate processes. Since NEIALs occur with a wide variety of different power and spectral characteristics, it is likely that there are many different mechanisms at work under different circumstances. One key element in generating the - NEIAL-causing - instabilities is the electron distribution. The type of aurora present during NEIAL events can be used to give an indication of the precipitating electron distribution, which can then be related to the instabilities causing the NEIALs. This comparison of different auroral forms concurrent with different types of NEIALs indicates that there are several consistencies between the shape of the NEIAL spectra and the type of auroral features present.

\subsection{Aurora-NEIALs comparison}

Poker Flat is located near the equatorward edge of the statistical auroral oval, and thus PFISR can commonly observe active growth phase auroral arcs and substorm-onset aurora. During active conditions - storm time - it is possible for the poleward edge of the auroral oval to extend south enough to be over Poker Flat, but this occurs less frequently. Therefore, the most common types of auroral features observed over Poker Flat - with associated NEIALs in the PFISR data - are the intense growth phase auroral arcs, such as those shown in Event 2 and Event 3 (Figs. 6 and 10). Also in the PFISR data, NEIALs are observed to occur with substormonset aurora that contain bright features, fast motions and small scales, such as those shown here in Event 1 (Fig. 3) and those reported in Michell et al. (2009) and Michell and Samara (2010).

The NEIALs that occurred during Event 2 and Event 3 showed significant similarity in the altitude ranges and spectral characteristics (Figs. 5 and 9). The NEIALs during these events both were constrained to low altitudes (between 200 

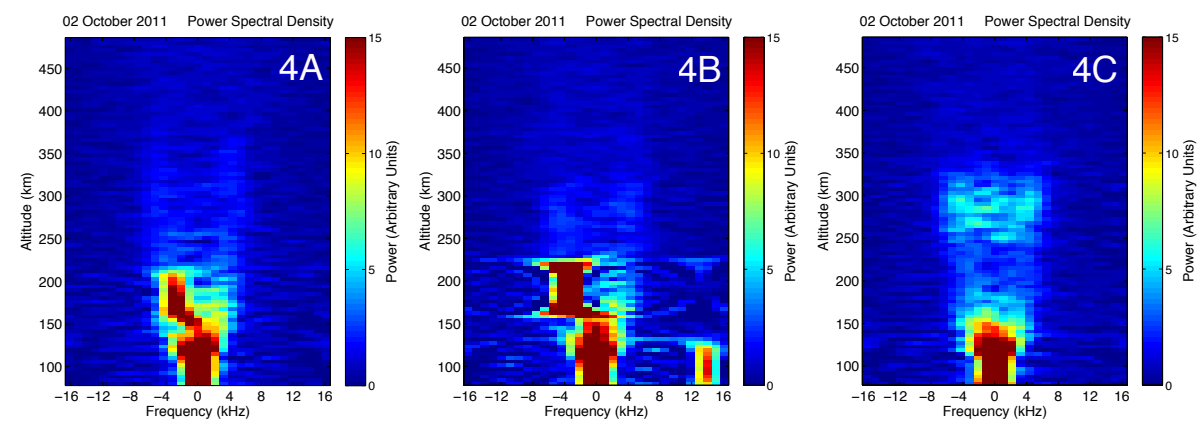

Figure 13. Event 4: NEIAL spectra from the times labeled 4A-4C in Fig. 12. The lower-altitude NEIAL has a highly asymmetric spectrum, while the higher-altitude NEIAL has no specific asymmetry and contains power throughout the region between the ion-acoustic peaks.

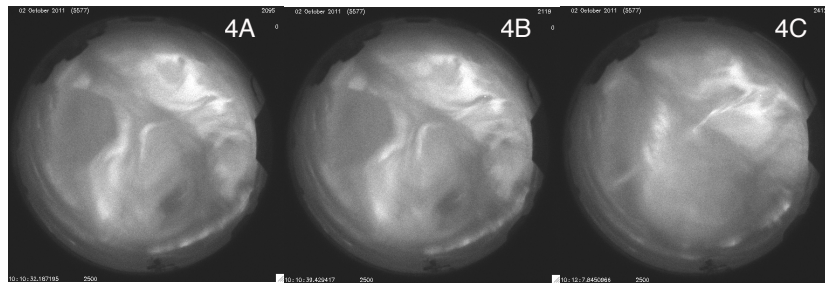

Figure 14. Event 4: all-sky images - taken on 2 October 2011 with a $557.7 \mathrm{~nm}$ filter - showing the dynamic overall structure of the aurora at the times of the NEIALs in the PFISR data (labeled 4A-4C). North is down and east is to the right.

and $400 \mathrm{~km}$ ), and they both contained power spread fairly evenly between the ion lines. These types of NEIALs are the most commonly observed with PFISR (Michell et al., 2008a, 2009; Michell and Samara, 2010). One thing to note about the altitude ranges of the NEIALs for Events 2 and 3 is that the "gap" region in Event 3 - the altitude range between the NEIALs at the same time - occurs between 250 and $350 \mathrm{~km}$ altitude. In Event 2, the NEIALs extend all the way through this altitude range, indicating either a difference in the local ionospheric conditions at that altitude or different driving mechanisms. The ionospheric conditions are very similar between these two events and the auroral structures showed many large-scale similarities, but there was one significant difference, specifically the presence of flickering aurora during Event 3. Flickering aurora has been observed many times from Poker Flat (Michell et al., 2012), but this is the first case where NEIALs have been observed to occur with flickering aurora.

Event 4 is different from previous NEIAL observations with PFISR in that the NEIALs occurred inside a broad region of pulsating aurora and not with active auroral structures (Fig. 14). The spectral shape of NEIALs 4A and 4B indicates that the downshifted ion line is much more strongly enhanced than the upshifted ion line (Fig. 13). This indicates enhanced ion-acoustic waves that are traveling upward. The spectral shape of NEIAL $4 \mathrm{C}$ is very similar to the shape of the NEIALs in Event 2, with power broadly spread between

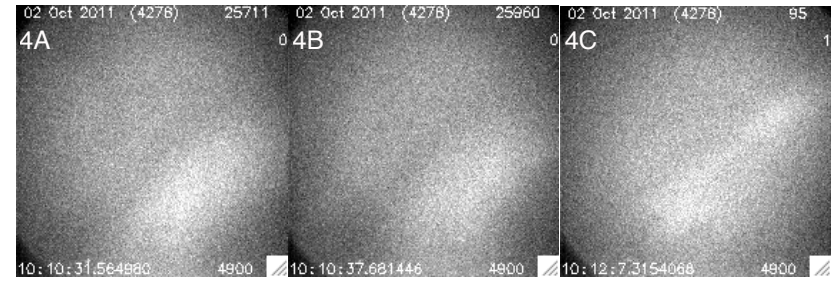

Figure 15. Event 4: narrow-field images $\left(15^{\circ} \mathrm{FOV}\right)-$ taken on 2 October 2011 with a $427.8 \mathrm{~nm}$ filter - showing the small-scale structure of the aurora at the times of the NEIALs in the PFISR data (labeled 4A-4C). The magnetic zenith - the location of the radar beam $\left(\sim 1^{\circ}\right.$ beamwidth $)$ - is located near the center of each image. Same orientation as Fig. 14.

the ion lines with an altitude of around $300 \mathrm{~km}$. The auroral structures visible in the narrow-field images (Fig. 15) at NEIALs 4A and 4B indicate that there was a dark region, where the NEIALs occurred. This is consistent with a downward current region (Michell et al., 2008b), where large fluxes of thermal electrons would be flowing upward. The strong enhancement observed in the downshifted shoulder is consistent with both the current-driven instability as well as the beam-driven Langmuir turbulence instability. An upward-moving electron beam - downward current - would produce upward-traveling (downshifted) ion-acoustic waves as well as downshifted Langmuir waves which can then decay into downshifted ion-acoustic waves and upshifted Langmuir waves.

The all-sky auroral images (Fig. 14) show the distinct dark region extending into the magnetic zenith for NEIALs 4A and $4 \mathrm{~B}$; however the overall auroral configuration is different for NEIAL $4 \mathrm{C}$, where there is a thin, bright arc that is near zenith. This thin, bright arc is the aurora associated with NEIAL 4C, which is similar to the NEIALs in Event 2, where they are associated with a thin, bright, large-scale auroral arc.

The NEIALs presented in Event 5 show "classic" NEIAL features (Grydeland et al., 2003, 2004; Blixt et al., 2005; Strømme et al., 2005), namely, asymmetric power enhancements, extending up to high altitudes (Fig. 16 and Fig. 17). 

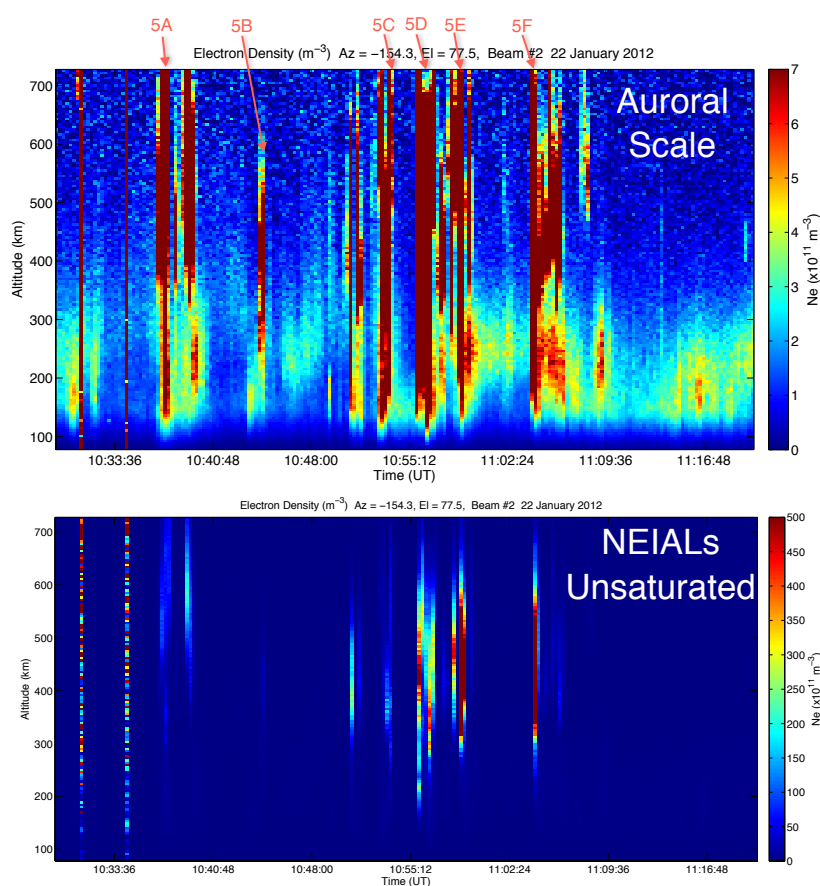

Figure 16. Event 5: top: PFISR electron density profiles, covering a time period of about 45 min with tall auroral rays in the magnetic zenith. The strong NEIAL returns can be seen to extend up to high altitudes $(>600 \mathrm{~km})$ in some cases. The times marked $5 \mathrm{~A}-5 \mathrm{~F}$ are the times of the NEIAL spectra shown in Fig. 17. Bottom: same time period with intensity scale set so the NEIALs are not oversaturated.

These type of NEIALs are believed to be associated with large fluxes of low-energy electrons (Collis et al., 1991; Rietveld et al., 1991; Blixt et al., 2005), which are consistent with the type of auroral features that were present during this event. The all-sky auroral images show that the main auroral emissions were primarily to the south of Poker Flat (top half of the image), and that the magnetic zenith was at the poleward edge of the aurora during these times (Fig. 18). The aurora consisted of curtains of active tall rays that appear to converge toward the magnetic zenith when viewed in the narrow-field images, indicating a large altitude extent (Fig. 19).

\section{Electron energy}

The average electron energy can be estimated using optical photometry from the multi-spectral auroral imaging data. Using one of the auroral emission line ratios discussed in Hecht et al. (2006) - namely the ratio of 427.8 to $844.6 \mathrm{~nm}$ - it is possible to estimate the average energy of the precipitating electrons. Using this ratio, we have made preliminary estimates of the average electron energy at the times of NEIALs 2 through 5. Table 4 shows a summary of the electron energy estimates for these NEIALs along with their altitudes, arranged in order of increasing altitude (the altitudes of the centers of the NEIALs are used). An anticorrelation is seen
Table 4. Summary of the NEIAL altitudes and the corresponding average electron energy calculated from the auroral photometry.

\begin{tabular}{clllr}
\hline Event & Date & Time (UT) & NEIAL alt. (km) & $\begin{array}{r}\text { Avg. } \mathrm{e}^{-} \\
\text {energy } \\
(\mathrm{keV})\end{array}$ \\
\hline 4a & 02 Oct 2011 & $10: 10: 30$ & 200 & 7.9 \\
3a & 02 Oct 2011 & $09: 07$ & 225 and 300 & 7.9 \\
2a & 28 Sep 2011 & $06: 07$ & 250 & 7.2 \\
4b & 02 Oct 2011 & $10: 12$ & 300 & 6.6 \\
2b & 28 Sep 2011 & $06: 25$ & 300 & 5.7 \\
3b & 02 Oct 2011 & $09: 12$ & 350 & 3.9 \\
5 & 22 Jan 2012 & $11: 00$ & 450 & 2.0 \\
\hline
\end{tabular}

between the calculated electron energy and the altitude of the NEIAL, where the lowest-altitude NEIALs correspond to the highest electron energies and the highest-altitude NEIALs correspond to the lowest energy electrons. This is consistent with the hypothesis that the high-altitude NEIALs are caused by large fluxes of low-energy electrons. These data indicate that there is a correlation between electron energy and NEIAL altitude and that further work should be done to quantify this relation with more statistics once the method of calculating electron energies from the optical photometry is refined further and calibration is fully worked out. It should be noted that these electron energy estimates are preliminary and that there could be systematic errors of up to a factor of 2 in the calculated energies. However the electron energies calculated are consistent with the precipitating electron energies that are typically measured in situ by electron spectrometers, for example on the FAST (Fast Auroral Snapshot Explorer) satellite (Carlson et al., 1998; McFadden et al., 1999) and on the Reimei satellite (Asamura et al., 2003, 2009), which adds a level of confidence to these estimates.

\subsection{Generation mechanisms}

The relationships between the different auroral forms and the characteristics of the NEIALs reveal consistencies between the auroral structures and the NEIAL-generating instabilities that are caused by the precipitating electrons.

The aurora present during Event 1 and Event 5 (Figs. 3 and 18) showed characteristics indicative of large fluxes of low-energy electrons, and the NEIALs for these two events showed similar features, with large asymmetries between the two shoulders as well as the enhanced returns extending to high altitudes. Event 1 contained flaming aurora, consistent with the prior observations of Blixt et al. (2005), where large fluxes of energy dispersed electrons deposit their energy at different altitudes, causing an apparent motion upwards as the lowest energies deposit their energy last, at the highest altitudes. The aurora in Event 5 showed tall rays (Fig. 19), which are indicative of localized regions of large fluxes of electrons with very broad energy spectra, with both highand low-energy electrons at the same time. The fluxes of the 

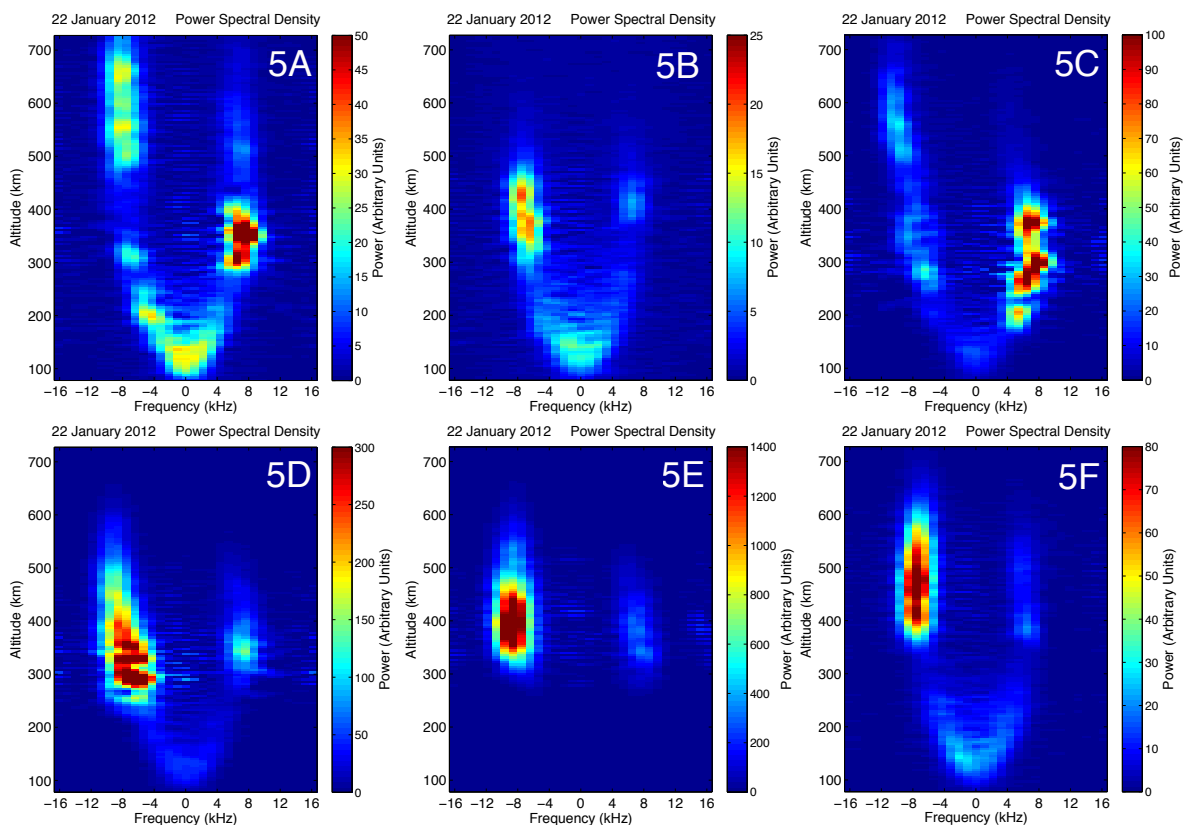

Figure 17. Event 5: NEIAL spectra from the times labeled 5A-5F in Fig. 16. The NEIAL spectra are all asymmetric, with the downshifted shoulder more enhanced than the upshifted shoulder. Note that the intensity scale is not the same for each spectra, for example, NEIAL 5E is orders of magnitude more intense than the others.

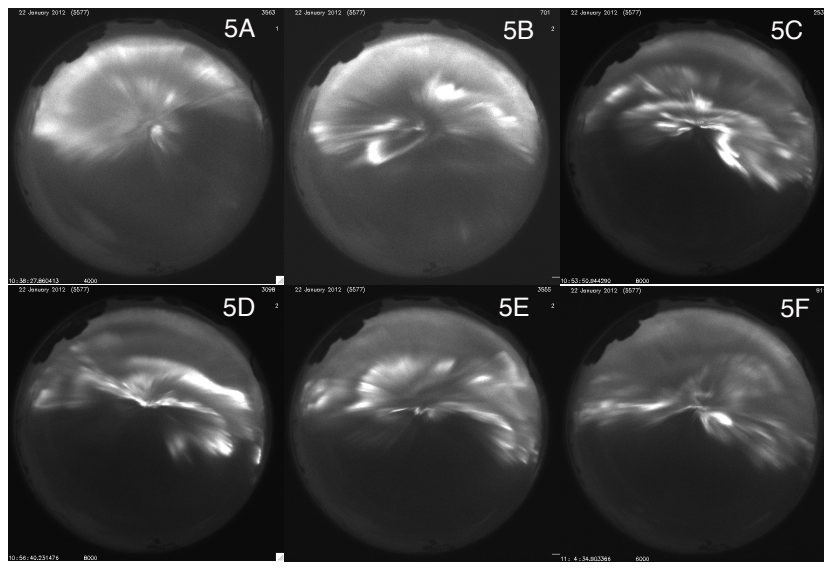

Figure 18. Event 5: all-sky images - taken on 22 January 2012 with a $557.7 \mathrm{~nm}$ filter - showing the dynamic overall structure of the aurora at the times of the NEIALs in the PFISR data (labeled $5 \mathrm{~A}-5 \mathrm{~F})$. North is down and east is to the right.

lower-energy electrons are indeed fairly large, such that they can produce visible aurora at high altitudes. Tall auroral rays are often observed to occur at the poleward edge of the auroral oval, as is often observed at the Sondrestrom radar, for example (Michell and Samara, 2013). These two events suggest that the high-altitude, large-asymmetry NEIALs - such as those previously observed with the ESR radar (Grydeland et al., 2003, 2004; Blixt et al., 2005) - are the result of an

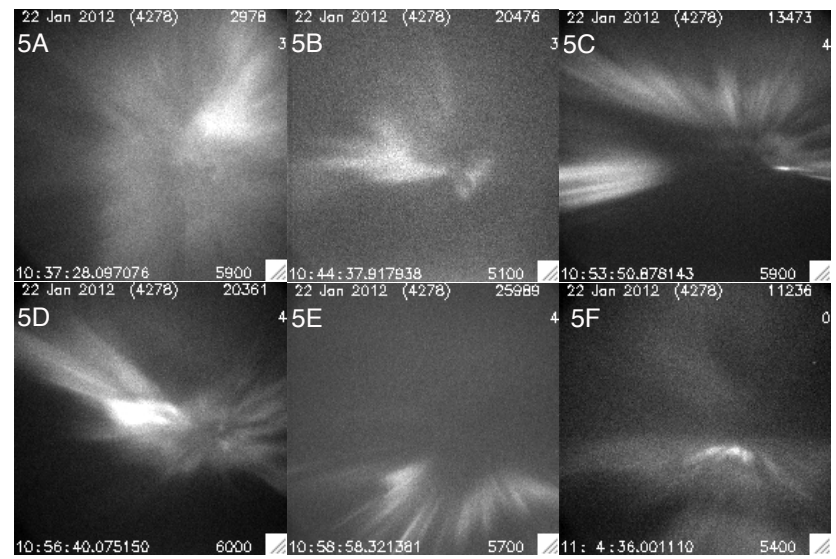

Figure 19. Event 5: narrow-field images $\left(15^{\circ} \mathrm{FOV}\right)$ - taken on 22 January 2012 with a $427.8 \mathrm{~nm}$ filter - showing the small-scale structure of the aurora at the times of the NEIALs in the PFISR data (labeled 5A-5CF). The magnetic zenith - the location of the radar beam $\left(\sim 1^{\circ}\right.$ beamwidth $)$ - is located near the center of each image. Same orientation as Fig. 18.

instability driven by significant fluxes of low energy $(\sim$ few hundred $\mathrm{eV}$ ) electrons. The electron energy estimates made here are also consistent with this because the average energy found was fairly low $(2 \mathrm{keV})$, indicating that there were significant electron fluxes below $1 \mathrm{keV}$.

The only way that the NEIALs observed in Event 1 and Event 5 could result from the electron-ion two-stream 
instability (Foster et al., 1988; Collis et al., 1991; Rietveld et al., 1991; Sedgemore-Schulthess et al., 1999) is if oppositely directed narrow $(<100 \mathrm{~m})$ filaments of current occur within the radar beam. As shown by Grydeland et al. (2004), the usual scenario is instead that both shoulders are simultaneously enhanced within the same volume. Alternate generation mechanisms - where both shoulders can be simultaneously enhanced - include the ion-ion two-stream instability (Wahlund et al., 1992) and the Langmuir turbulence theory (Forme, 1999). These two events have no real power enhancements in the zero-Doppler region, although there are some noise signals which are artifacts of the FFT processing and do not represent real backscattered power in that frequency range.

The other three events show similarity in that the enhanced power is spread between the ion-acoustic peaks. Event 2 and Event 3 are similar, except the altitude ranges are slightly different (Figs. 5 and 9). These two events (2 and 3) are likely caused by the same mechanism, and the most likely candidate in these cases is the Langmuir turbulence theory, which is consistent with the recent work by Akbari et al. (2012, 2013) and Isham et al. (2012) and can account for the enhancements of power between the ion-acoustic peaks. The aurora during these times is consistent with Langmuir turbulence in that it was strong and localized, with a large portion of high-energy electrons, capable of penetrating down into the lower ionosphere (below the $\mathrm{F}$ region and into the $\mathrm{E}$ region). The electron energy estimates made for these NEIALs are consistent with this in that the average energy was found to be rather high $(\sim 6-8 \mathrm{keV})$. The two distinct altitude ranges of NEIALs present in Event 3 (Fig. 8) could be the result of the presence of flickering aurora. In the flickering auroral event, there are two separate precipitating electrons populations present, a background one and the modulated (flickering) one. Therefore the two separate altitude ranges are caused by the two separate electrons populations, with the higher-energy one - likely the background population - penetrating to lower altitude, causing instabilities lower down, and the modulating electron population is slightly lower in energy and does not penetrate as low in altitude.

Event 4 (Fig. 13) shows some distinct differences as well as similarities with the other NEIAL events presented, the main differences being the type of auroral structures present - large-scale pulsating aurora - and the asymmetric, lowaltitude (150 to $200 \mathrm{~km}$ ) strong returns in NEIALs $4 \mathrm{~A}$ and 4B. NEIAL $4 \mathrm{C}$ is similar to those in Event 2 and Event 3 in that it contains power throughout the region between the ion-acoustic peaks and is near the $\mathrm{F}$ region peak. It is possible that NEIALs $4 \mathrm{~A}$ and $4 \mathrm{~B}$, were caused by a current-driven instability if there was a strong localized downward current (upward-moving electrons) that caused the strong upward propagating ion-acoustic waves, leading to the non-thermal spectra observed. The auroral structures present at this time show a distinct dark stripe, consistent with downward current regions (Michell et al., 2008b). The all-sky images at the time of NEIAL $4 \mathrm{C}$ are slightly different and do not show the same dark stripe but instead show a thin bright stripe near zenith. This indicates a particular type of electron precipitation, which is most likely driving Langmuir turbulence that then causes NEIAL 4C.

The structure of the aurora and the characteristics of the NEIALs can be used to determine the most likely generation mechanisms for the NEIALs. In some instances it is more likely that the current-driven instability is causing the NEIALs, while at other times it is most likely the Langmuir turbulence, either strong or weak. It is also possible - and likely - that at times there are multiple generation mechanisms occurring, especially given the dynamic and rapidly changing nature of the auroral features.

\section{Conclusions}

Combining auroral imaging with NEIAL observations helps improve our understanding of the mechanisms responsible for generating different types of NEIALs. The spectral characteristics of the NEIALs combined with their accompanying auroral features are consistent with multiple NEIAL generation mechanisms existing in the ionosphere under different circumstances.

The most common NEIALs observed in the PFISR data are the ones at fairly low altitudes $-\mathrm{F}$ region or below - that have power at, and spread between, the ion-acoustic peaks. These NEIALs are most often associated with active, structured auroral arcs, such as substorm growth phase and onset arcs, where the average precipitating electron energy tends to be higher. This type of NEIAL has also been observed with the EISCAT radars (Isham et al., 2012; Rietveld et al., 2002), although less frequently there than at PFISR due to the location of the radars in relation to the auroral oval. The second category of NEIALs described contains those that have been reported on more frequently with the EISCAT radars. These NEIALs extend to high altitudes $(600 \mathrm{~km}$ or more) and often have large asymmetries in the power enhancements between the two ion-acoustic shoulders. These NEIALs are associated with aurora that contains large fluxes of low-energy electrons, as can happen in poleward boundary intensifications as well as at substorm onset. The dynamic processes that occur during substorm onsets can generate both types of NEIALs, and it is therefore likely that multiple NEIAL generation mechanisms can occur within substorm-onset aurora. There are other types of NEIALs observed with PFISR, such as that in Event 4, that do not fit neatly into either of these two categories, although NEIALs 4A and 4B are likely caused by upward fluxes of low-energy electrons.

Preliminary auroral photometry analyses revealed that there is an anticorrelation between the altitude of the NEIALs and the energy of the electrons. This is consistent with the hypotheses presented here regarding generation 
mechanisms, namely that the Langmuir turbulence causes the lower-altitude NEIALs (higher-energy electrons) and that large fluxes of low-energy electrons cause the high-altitude NEIALs.

These observations show that there is a correlation between the auroral structures and the type of NEIALs observed, and that the auroral structures present during NEIAL events are consistent with the inferred NEIAL generation mechanisms. In addition, the auroral features can be used to determine which of the possible generation mechanisms is the most likely one in each case, including the distinction between strong (high electron energy) and weak (low electron energy) Langmuir turbulence. These observations lead into several future studies to be done. These include quantifying the electron precipitation using emission line ratios at the times of NEIALs and to do this over a large sample size of NEIAL-aurora events as well as repeating these highresolution auroral observations at the EISCAT radar facilities to compare with the NEIALs observed there to put the PFISR work in better context with previous observations.

Acknowledgements. This work was supported by National Science Foundation grant no. AGS-1139135. The imagers used were acquired under National Science Foundation grant no. ATM-0923412. The authors would like to thank SRI International, and specifically C. Heinselman and M. Nicolls for assisting us in PFISR operations and data availability. Thanks also to the University of Alaska, Fairbanks/Geophysical Institute for the use of their facilities and imagers at Poker Flat, AK, particularly D. Hampton for his assistance in imager operations and data collection. R. Michell thanks G. Grubbs for computing the initial electron energy estimates from the optical data.

Topical Editor K. Hosokawa thanks M. Rietveld and one anonymous referee for their help in evaluating this paper.

\section{References}

Akbari, H., Semeter, J. L., Dahlgren, H., Diaz, M., Zettergren, M., Strømme, A., Nicolls, M. J., and Heinselman, C.: Anomalous ISR echoes preceding auroral breakup: Evidence for strong Langmuir turbulence, Geophys. Res. Lett., 39, L03102, doi:10.1029/2011GL050288, 2012.

Akbari, H., Semeter, J. L., Nicolls, M. J., Broughton, M., and Labelle, J. W.: Localization of auroral Langmuir turbulence in thin layers, J. Geophys. Res., 118, 3576-3583, doi:10.1002/jgra.50314, 2013.

Asamura, K., Tsujita, D., Tanaka, H., Saito, Y., Mukai, T., and Hirahara, M.: Auroral particle instrument onboard the index satellite, Adv. Space Res., 32, 375-378, doi:10.1016/S02731177(03)90275-4, 2003.

Asamura, K., Chaston, C. C., Itoh, Y., Fujimoto, M., Sakanoi, T., Ebihara, Y., Yamazaki, A., Hirahara, M., Seki, K., Kasaba, Y., and Okada, M.: Sheared flows and small-scale Alfvén wave generation in the auroral acceleration region, Geophys. Res. Lett., 36, 5105, doi:10.1029/2008GL036803, 2009.
Bahcivan, H. and Cosgrove, R.: Enhanced ion acoustic lines due to strong ion cyclotron wave fields, Ann. Geophys., 26, 2081-2095, doi:10.5194/angeo-26-2081-2008, 2008.

Blixt, E. M., Grydeland, T., Ivchenko, N., Hagfors, T., La Hoz, C., Lanchester, B. S., Løvhaug, U. P., and Trondsen, T. S.: Dynamic rayed aurora and enhanced ion-acoustic radar echoes, Ann. Geophys., 23, 3-11, doi:10.5194/angeo-23-3-2005, 2005.

Cabrit, B., Opgenoorth, H., and Kofman, W.: Comparison between EISCAT UHF and VHF backscattering cross section, J. Geophys. Res., 101, 2369-2376, doi:10.1029/95JA02175, 1996.

Carlson, C. W., McFadden, J. P., Ergun, R. E., Temerin, M., Peria, W., Mozer, F. S., Klumpar, D. M., Shelley, E. G., Peterson, W. K., Moebius, E., Elphic, R., Strangeway, R., Cattell, C., and Pfaff, R.: FAST observations in the downward auroral current region: Energetic upgoing electron beams, parallel potential drops, and ion heating, Geophys. Res. Lett., 25, 2017-2020, 1998.

Collis, P. N., Haggstrom, I., Kaila, K., and Rietveld, M. T.: EISCAT radar observations of enhanced incoherent scatter spectra and their relation to red aurora and field-aligned currents, Geophys. Res. Lett., 18, 1031-1034, 1991.

Dahlgren, H., Semeter, J. L., Marshall, R. A., and Zettergren, M.: The optical manifestation of dispersive field-aligned bursts in auroral breakup arcs, J. Geophys. Res.-Space, 118, 4572-4582, doi:10.1002/jgra.50415, 2013.

Daldorff, L. K. S., Pécseli, H. L., and Trulsen, J.: Nonlinearly generated plasma waves as a model for enhanced ion acoustic lines in the ionosphere, Geophys. Res. Lett., 34, L18101, doi:10.1029/2007GL031513, 2007.

Forme, F. R. E.: A new interpretation of the origin of enhanced ion acoustic fluctuations in the upper ionosphere, Geophys. Res. Lett., 20, 2347-2350, doi:10.1029/93GL02490, 1993.

Forme, F. R. E.: Parametric decay of beam-driven Langmuir wave and enhanced ion-acoustic fluctuations in the ionosphere: a weak turbulence approach, Ann. Geophys., 17, 1172-1181, doi:10.1007/s00585-999-1172-4, 1999.

Foster, J. C., del Pozo, C., Groves, K., and Saint Maurice, J.-P.: Radar observations of the onset of current driven instabilities in the topside ionosphere, Geophys. Res. Lett., 15, 160-163, 1988.

Grydeland, T., La Hoz, C., Hagfors, T., Blixt, E. M., Saito, S., Strømme, A., and Brekke, A.: Interferometric observations of filamentary structures associated with plasma instability in the auroral ionosphere, Geophys. Res. Lett., 30, 1338, doi:10.1029/2002GL016362, 2003.

Grydeland, T., Blixt, E. M., Løvhaug, U. P., Hagfors, T., La Hoz, C., and Trondsen, T. S.: Interferometric radar observations of filamented structures due to plasma instabilities and their relation to dynamic auroral rays, Ann. Geophys., 22, 1115-1132, doi:10.5194/angeo-22-1115-2004, 2004.

Guio, P. and Forme, F.: Zakharov simulations of Langmuir turbulence: Effects on the ion-acoustic waves in incoherent scattering, Phys. Plasmas, 13, 122902, doi:10.1063/1.2402145, 2006.

Hecht, J. H., Strickland, D. J., and Conde, M. G.: The application of ground-based optical techniques for inferring electron energy deposition and composition change during auroral precipitation events, J. Atmos. Sol.-Terr. Phy., 68, 1502-1519, doi:10.1016/j.jastp.2005.06.022, 2006.

Isham, B., Rietveld, M. T., Guio, P., Forme, F. R. E., Grydeland, T., and Mjølhus, E.: Cavitating Langmuir Turbulence 
in the Terrestrial Aurora, Phys. Rev. Lett., 108, 105003, doi:10.1103/PhysRevLett.108.105003, 2012.

McFadden, J. P., Carlson, C. W., and Ergun, R. E.: Microstructure of the auroral acceleration region as observed by FAST, J. Geophys. Res., 104, 14453-14480, doi:10.1029/1998JA900167, 1999.

Michell, R. G. and Samara, M.: High-resolution observations of naturally enhanced ion acoustic lines and accompanying auroral fine structures, J. Geophys. Res., 115, A03310, doi:10.1029/2009JA014661, 2010.

Michell, R. G. and Samara, M.: Observability of NEIALs with the Sondrestrom and Poker Flat incoherent scatter radars, J. Atmos. Sol.-Terr. Phy., 105, 299-307, doi:10.1016/j.jastp.2012.12.008, 2013.

Michell, R. G., Lynch, K. A., Heinselman, C. J., and StenbaekNielsen, H. C.: PFISR nightside observations of naturally enhanced ion acoustic lines, and their relation to boundary auroral features, Ann. Geophys., 26, 3623-3639, doi:10.5194/angeo-263623-2008, 2008a.

Michell, R. G., Lynch, K. A., and Stenbaek-Nielsen, H. C.: Groundbased observational signature of a downward current channel in an active auroral arc, Geophys. Res. Lett., 35, 8101, doi:10.1029/2008GL033596, 2008b.

Michell, R. G., Lynch, K. A., Heinselman, C. J., and StenbaekNielsen, H. C.: High time resolution PFISR and optical observations of naturally enhanced ion acoustic lines, Ann. Geophys., 27, 1457-1467, doi:10.5194/angeo-27-1457-2009, 2009.

Michell, R. G., McHarg, M. G., Samara, M., and Hampton, D. L.: Spectral analysis of flickering aurora, J. Geophys. Res., 117, A03321, doi:10.1029/2011JA016703, 2012.

Rees, M. H. and Luckey, D.: Auroral electron energy derived from ratio of spectroscopic emissions. I - Model computations, J. Geophys. Res., 79, 5181-5186, doi:10.1029/JA079i034p05181, 1974.

Rietveld, M. T., Collis, P. N., and St.-Maurice, J.-P.: Naturally enhanced ion acoustic waves in the auroral ionosphere observed with the EISCAT 933-MHz radar, J. Geophys. Res., 96, 1929119305, 1991.
Rietveld, M. T., Isham, B., Grydeland, T., La Hoz, C., Leyser, T. B., Honary, F., Ueda, H., Kosch, M., and Hagfors, T.: HF-Pumpinduced parametric instabilities in the auroral E-region, Adv. Space Res., 29, 1363-1368, doi:10.1016/S0273-1177(02)001862, 2002.

Sedgemore-Schulthess, K. J. F., Lockwood, M., Trondsen, T. S., Lanchester, B. S., Rees, M. H., Lorentzen, D. A., and Moen, J.: Coherent EISCAT Svalbard Radar spectra from the dayside cusp/cleft and their implications for transient field-aligned currents, J. Geophys. Res., 104, 24613-24624, 1999.

Semeter, J., Zettergren, M., Diaz, M., and Mende, S.: Wave dispersion and the discrete aurora: New constraints derived from high-speed imagery, J. Geophys. Res., 113, 12208, doi:10.1029/2008JA013122, 2008.

Strømme, A.: Naturally enhanced wave modes observed with the eiscat svalbard radar, Ph.D. thesis, University of Troms $\varnothing, 2004$.

Strømme, A., Belyey, V., Grydeland, T., La Hoz, C., Løvhaug, U. P., and Isham, B.: Evidence of naturally occurring wavewave interactions in the polar ionosphere and its relation to naturally enhanced ion acoustic lines, Geophys. Res. Lett., 32, 5103, doi:10.1029/2004GL020239, 2005.

Sullivan, J. M., Lockwood, M., Lanchester, B. S., Kontar, E. P., Ivchenko, N., Dahlgren, H., and Whiter, D. K.: An optical study of multiple NEIAL events driven by low energy electron precipitation, Ann. Geophys., 26, 2435-2447, doi:10.5194/angeo-262435-2008, 2008.

Wahlund, J.-E., Forme, F. R. E., Opgenoorth, H. J., Persson, M. A. L., Mishin, E. V., and Volokitin, A. S.: Scattering of electromagnetic waves from a plasma - Enhanced ion acoustic fluctuations due to ion-ion two-stream instabilities, Geophys. Res. Lett., 19, 1919-1922, 1992. 